\title{
Highest extent of lateral and medial heads of triceps brachii muscle
}

\author{
LOVESH, S. ${ }^{*}$, KAUR, D. ${ }^{1}$, JAIN, $M .^{1}$ and PANDEY, S. M. ${ }^{2}$
}

\author{
${ }^{1}$ Department of Anatomy, Maharaja Agrasen Medical College, Agroha, Hisar, Haryana-125047, India \\ ${ }^{2}$ Department of Community Medicine, Maharaja Agrasen Medical College, Agroha, Hisar, Haryana-125047, India \\ *E-mail: drlovesh@gmail.com; dr.lovesh.anatomy@mamc.edu.in
}

\begin{abstract}
Introduction:Various studies have been done on triceps brachii muscle but the description of the highest extent of lateral and medial head of triceps brachii muscle remained unexplored that is why this study was undertaken to know the extent of their proximal attachments in relation to anatomical neck of humerus and capsule of shoulder joint. Materials and Methods: The shoulder region of 50 formalin fixed upper limbs were dissected to explore the capsule of shoulder joint to reach the highest extent of lateral \& medial head of triceps brachii muscle where the nature of fibres, fleshy or tendinous was noted. Oblique and vertical distances of proximal attachment of lateral \& medial head of triceps brachii muscle to the anatomical neck of humerous was measured with the help of a sliding caliper. Results: Medial head of triceps brachii muscle in all the cases was fleshy in origin while that of lateral head; fibres were fleshy and tendinous in $82 \%$ \& $18 \%$ of cases, respectively. Fibres of lateral and medial head were blending with the capsule of shoulder joint in $28 \%$ \& $6 \%$ of cases respectively. Maximum cases of lateral head were having their oblique and vertical distances between $21-40 \mathrm{~mm}(64 \%$ \& $58 \%$ respectively) while those for medial head were $>40 \mathrm{~mm}(68 \% \& 74 \%$ respectively $)$. Conclusion: Accurate knowledge of these anatomical patterns of triceps brachii muscle are of considerable clinical importance in the conduct of reparative open access and arthroscpic surgeries around the shoulder and the fracture management of the upper end of humerus.
\end{abstract}

Keywords: triceps brachii muscle, lateral head, medial head, proximal attachment, anatomical neck.

\section{Introduction}

Triceps brachii muscle (TBM) arises by three heads; long, lateral and medial. Long head of which arises from infraglenoid tubercle of scapula, blending above with glenohumeral ligament of the capsule of shoulder joint (SJ). Lateral head ( $\mathrm{LH})$ of TBM arises from a narrow ridge on posterior surface of the shaft of humerus superior to radial groove; and from lateral intermuscular septum. Its attachment on humerus ascends with varying obliquity from its lateral border, above radial groove and behind deltoid tuberosity, to the surgical neck of humerus, medial to the insertion of teres minor muscle. Medial head $(\mathrm{MH})$ of TBM has an extensive origin from the entire surface of the shaft of humerus inferior to radial groove to with in $25 \mathrm{~mm}$ of trochlea, from medial border of humerus, medial intermuscular septum and the lower part of lateral intermuscular septum. Entire muscle inserts on olecranon process of ulna and is chief extensor of the forearm. Radial groove is a shallow groove which interrupts the middle third of medial border of humerus and crosses it obliquely, passing downwards and forwards from its posterior to anterior surface. Radial nerve and profunda brachii vessels run downwards and laterally in this groove. (JOHNSON, 2008)

Various studies have been done on TBM (CHEEMA and SINGLA, 2011; NAYAK, KRISHNAMURTHY, KUMAR et al., 2008; SAWANT, 2013) but the description of the highest extent of its $\mathrm{LH}$ and $\mathrm{MH}$ remained unexplored, that is why this study was undertaken to know the extent of proximal attachment of $\mathrm{MH}$ and $\mathrm{LH}$ in relation to anatomical neck of humerus and capsule of SJ.

\section{Materials and Methods}

Present study was conducted on 50 formalin fixed upper limbs (25 right and 25 left) obtained from dissecting room. Limbs with deformity, damage or any injury mark were not included in the study. Limbs were numbered from one to 50 and the side of the limb was noted. Scapular region was exposed and deltoid muscle was incised from spinous and acromian processess of scapula and reflected downwards to expose the structures under deltoid muscle. Insertion of teres minor and infraspinatous muscles were cleared of by removing their overlying fascia. Teres minor muscle was incised near its insertion and reflected inferomedially to expose the capsule of SJ, which was cut-opened by giving a nick and extending it longitudinally up and down. Axillary nerve and posterior circumflex humeral vessels were incised near their entry into deltoid muscle to view the highest attachments of $\mathrm{MH}$ and LH of TBM. At their proximal attachments, nature of muscle fibres, tendinous or fleshy, was noted. Following measurements were taken with the help of a sliding caliper (measuring up to $1 \mathrm{~mm})$ :

1. Oblique distance (OD) of proximal attachment of $\mathrm{LH}$ and $\mathrm{MH}$ to the lowermost part of anatomical neck of humerus, medially.

2. Vertical distance (VD) from proximal attachment of LH and $\mathrm{MH}$ to the anatomical neck of humerus.

Collected data were recorded and analysed statistically using "chi square t test" and "two sample test" using "SYSTAT" software version 12 . 


\section{Results}

The results were showed in Tables 1 and 2 and Figure 1.

\subsection{Inference}

1.In all the cases $\mathrm{MH}$ was fleshy in origin.

2. LH took a fleshy and tendinous origin in $82 \%$ and $18 \%$ of cases respectively. Statistically they have no association with the side of limb $(\mathrm{p}=1.00)$.

3. Statistically significant $(\mathrm{p}=0.028)$ difference was observed in the incidence of origin of LH (28\%) (Figure 1) and $\mathrm{MH}(6 \%)$; where fibres of origin were blending with the capsule of SJ. Statistically, association $(\mathrm{p}=0.52)$ of these blending fibres of $\mathrm{LH}$ and $\mathrm{MH}$ with the side of limb was not significant

4. Mean OD was more on left side, both in $\mathrm{LH}$ and $\mathrm{MH}$, but these differences were not statistically significant with two sample test (for LH, $\mathrm{p}=0.26 \& \mathrm{t}=1.26$ and for $\mathrm{MH}, \mathrm{p}=0.404 \& \mathrm{t}=0.843)$.

5. Mean VD was more on the left side in both LH and $\mathrm{MH}$, but these differences were not significant statistically with two sample test (for $\mathrm{LH}, \mathrm{p}=0.216 \& \mathrm{t}=1.260$ and for $\mathrm{MH}, \mathrm{p}=0.896 \& \mathrm{t}=0.130)$.

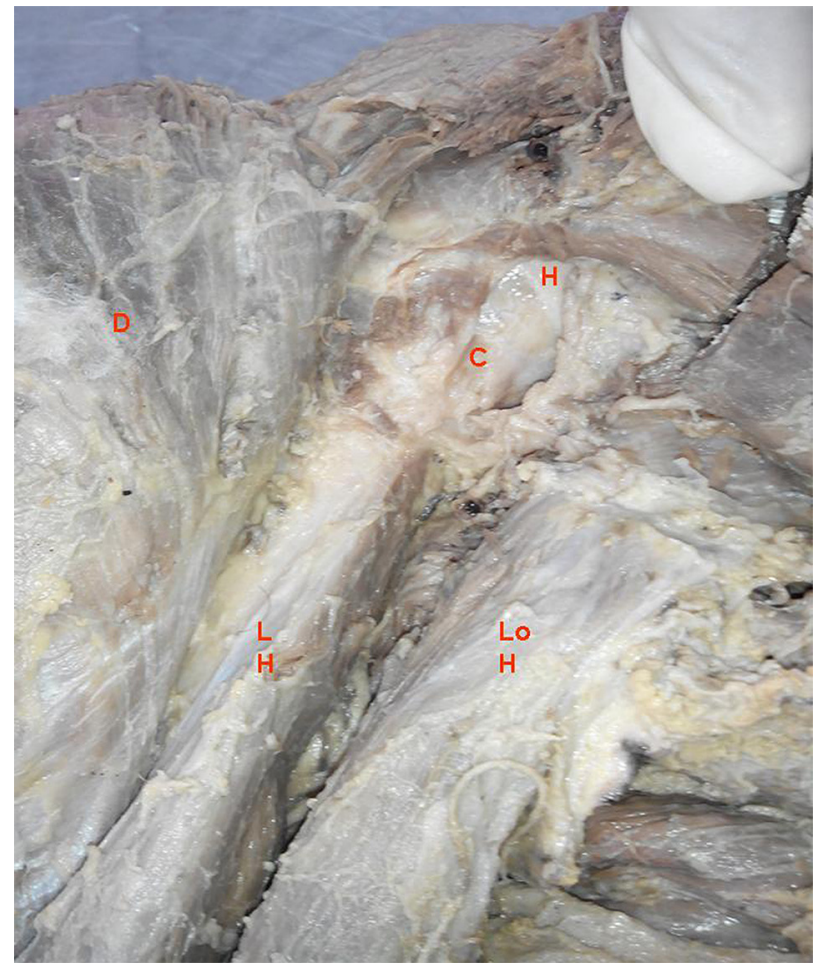

Figure 1. Show fibres of LH blending with the capsule of SJ.

Table 1. Showing frequency of nature of fibres and mean of OD \& VD of LH \& MH.

\begin{tabular}{|c|c|c|c|c|c|c|c|}
\hline \multirow[b]{2}{*}{ S.no } & \multirow[b]{2}{*}{ Parameters } & \multicolumn{3}{|c|}{ LH } & \multicolumn{3}{|c|}{ MH } \\
\hline & & $\mathrm{R}_{\mathrm{n}}=25(\%)$ & $\mathrm{L} n=25(\%)$ & $\begin{array}{c}\text { Total } \\
\mathrm{n}=\mathbf{5 0}(\%)\end{array}$ & $\mathrm{R}_{\mathrm{n}}=\mathbf{2 5 ( \% )}$ & $\mathrm{L} n=25(\%)$ & $\begin{array}{c}\text { Total } \\
\mathbf{n}=\mathbf{5 0}(\%)\end{array}$ \\
\hline 1 & $\begin{array}{c}\text { No (\%) of cases with } \\
\text { fleshy origin }\end{array}$ & $20(80 \%)$ & $21(84 \%)$ & $41(82 \%)$ & $25(100 \%)$ & $25(100 \%)$ & $50(100 \%)$ \\
\hline 2 & $\begin{array}{l}\text { No }(\%) \text { of cases with } \\
\text { tendinous origin }\end{array}$ & $5(20 \%)$ & $4(16 \%)$ & $9(18 \%)$ & $0(0 \%)$ & $0(0 \%)$ & $0(0 \%)$ \\
\hline 3 & $\begin{array}{l}\text { No }(\%) \text { of cases with } \\
\text { fibers blending with } \\
\text { capsule of SJ }\end{array}$ & $8(32 \%)$ & $6(24 \%)$ & $14(28 \%)$ & $l(4 \%)$ & $2(8 \%)$ & $3(6 \%)$ \\
\hline 4 & $\begin{array}{c}\text { Mean } \pm \text { SD (Range) } \\
\text { of OD in } \mathrm{mm}\end{array}$ & $\begin{array}{c}26 \pm 0.65 \\
(17-37)\end{array}$ & $\begin{array}{l}29 \pm 0.60 \\
(22-43)\end{array}$ & $\begin{array}{c}28 \pm 0.63 \\
(17-43)\end{array}$ & $\begin{array}{l}46 \pm 1.49 \\
(21-70)\end{array}$ & $\begin{array}{c}50 \pm 1.530 \\
(25-87) \\
\end{array}$ & $\begin{array}{l}48 \pm 1.50 \\
(21-87)\end{array}$ \\
\hline 5 & $\begin{array}{c}\text { Mean } \pm \text { SD (Range) of } \\
\text { VD in } \mathrm{mm}\end{array}$ & $\begin{array}{c}27 \pm 0.65 \\
(18-42) \\
\end{array}$ & $\begin{array}{l}29 \pm 0.67 \\
(19-45) \\
\end{array}$ & $\begin{array}{c}28 \pm 0.66 \\
(18-45) \\
\end{array}$ & $\begin{array}{l}50 \pm 1.60 \\
(21-84) \\
\end{array}$ & $\begin{array}{l}51 \pm 1.66 \\
(23-89) \\
\end{array}$ & $\begin{array}{l}51 \pm 1.61 \\
(21-23) \\
\end{array}$ \\
\hline
\end{tabular}

R: Right side, L: Left side, n: number of cases.

Table 2. Showing the range distribution of OD \&VD of LH \& MH.

\begin{tabular}{|c|c|c|c|c|c|c|c|}
\hline & \multirow[b]{2}{*}{ Range (mm) } & \multicolumn{3}{|c|}{ LH } & \multicolumn{3}{|c|}{ MH } \\
\hline & & $\mathrm{R} n=25(\%)$ & $\mathrm{L} n=25(\%)$ & $\begin{array}{c}\text { Total } \\
\mathbf{n}=\mathbf{5 0}(\%)\end{array}$ & $\mathrm{R}_{\mathrm{n}}=25(\%)$ & $\mathrm{L} n=25(\%)$ & $\begin{array}{c}\text { Total } \\
\mathbf{n}=\mathbf{5 0}(\%)\end{array}$ \\
\hline \multirow{4}{*}{ OD } & 0 & $8(32 \%)$ & $6(24 \%)$ & $14(28 \%)$ & $\mathrm{l}(4 \%)$ & $2(8 \%)$ & $3(6 \%)$ \\
\hline & $1-20$ & $3(12 \%)$ & $0(0 \%)$ & $3(6 \%)$ & $0(0 \%)$ & $0(0 \%)$ & $0(0 \%)$ \\
\hline & $21-40$ & $14(56 \%)$ & $18(72 \%)$ & $32(64 \%)$ & $8(32 \%)$ & $5(20 \%)$ & $13(26 \%)$ \\
\hline & $>40$ & $0(0 \%)$ & $1(4 \%)$ & $\mathrm{l}(2 \%)$ & $16(64 \%)$ & $18(72 \%)$ & $34(68 \%)$ \\
\hline \multirow{4}{*}{ VD } & 0 & $8(32 \%)$ & $6(24 \%)$ & $14(28 \%)$ & $\mathrm{l}(4 \%)$ & $2(8 \%)$ & $3(6 \%)$ \\
\hline & $1-20$ & $3(12 \%)$ & $2(8 \%)$ & $5(10 \%)$ & $0(0 \%)$ & $0(0 \%)$ & $0(0 \%)$ \\
\hline & $21-40$ & $13(52 \%)$ & $16(64 \%)$ & $29(58 \%)$ & $6(24 \%)$ & $4(16 \%)$ & $10(20 \%)$ \\
\hline & $>40$ & $1(4 \%)$ & $1(4 \%)$ & $2(4 \%)$ & $18(72 \%)$ & $19(76 \%)$ & $37(74 \%)$ \\
\hline
\end{tabular}


6. Mean VD was more than mean OD, both in the cases of $\mathrm{LH}$ and $\mathrm{MH}$ of TBM but these differences were insignifant statistically with two sample t-test.

7. Maximum cases of $\mathrm{LH}$ were having their OD and VD between $21-40 \mathrm{~mm}$ ( $64 \%$ \& $58 \%$ respectively) while in case of $\mathrm{MH}$, they were $>40 \mathrm{~mm}(68 \% \& 74 \%$ respectively).

\section{Discussion}

Variations of TBM are relatively uncommon as compared to biceps brachii muscle, yet they have occasionally being reported (CHEEMA and SINGLA, 201 1; NAYAK, KRISHNAMURTHY, KUMAR et al., 2008; SAWANT, 2013). After a thorough search of literature, no matching result in the variation of the highest extent of origin of LH \& MH of TBM, was found. However, Macalister has mentioned a variation of TBM with a fourth head arising from medial part of humerus; additionally, he also described a variation where long head of TBM was attached to capsule of SJ (MACALISTER, 1875).

$\mathrm{LH}$ takes origin from the humerus by tendinous fibres (JOHNSON, 2008) but in the presnt study it took a fleshy origin in $82 \%$ of cases.

Embryologically, during the fifth week of development, mesoderm invades the upper limb bud to further condense into ventral and dorsal muscle masses. Triceps and biceps musculature is derived from dorsal and ventral muscle masses of the upper limb bud, respectively (SCHOENWOLF, BLEYL, BRAUER et al., 2009). During this time of development extended origin of different heads of triceps brachii muscle might have occurred.

\section{Conclusion}

Accurate knowledge of these anatomical patterns of TBM are of considerable clinical importance in the conduct of reparative open access and arthroscpic surgeries around the shoulder and fracture management of upper end of humerus.

\section{References}

CHEEMA, P. and SINGLA, R. Four headed triceps brachii muscle. International Journal of Anatomical Variations, 2011, vol. 4, p. 43-44.

JOHNSON, D. Gray's anatomy: the anatomical basis of clinical practice. Edinburg: Churchill Livingstone, 2008. p. 798-826.

MACALISTER, A. Additional observations on muscular anomalies in buman anatomy (third series), with a catalogue of the principal muscular variations hitherto published. Dublin: Royal Irish Academy, 1875. p. 1-134. Transactions of the Royal Irish Academy, 25.

NAYAK, SR., KRISHNAMURTHY, A., KUMAR, M., PRABHU, LV., SARALAYA, V. and THOMAS, MM. Four headed biceps and triceps brachii muscles, with neurovascular variation. Anatomical Science International, 2008, vol. 83, n. 2, p. 107-111. PMid:18507620.

SAWANT, SP. Study of variant heads of triceps muscle with its developmental basis. International Journal of Analytical. Pharmaceutical and Biomedical Sciences, 2013, vol. 2, p. 23-26.

SCHOENWOLF, GC., BLEYL, SB., BRAUER, PR. and FRANCISWEST, PH. Larsen's human embryology. Philadelphia: Churchill Livingstone, 2009. p. 241-242. 